\title{
Yoga Benefits for Health
}

\author{
Razia Saleem $^{1 *}$
}

\section{ABSTRACT}

Nowadays yoga become more popular among the all age peoples it employs a broad holistic approach that focuses on teaching people a new lifestyle, way of thinking, and way of being in the world. In the process, however, it is also found to bring a myriad of healing effects. By attending to practices for improving, regaining or retaining general good health, a person is likely to find that some of his more specific difficulties tend to disappear. Many of the healing effects of yoga are clinically verified. the most important benefits of yoga is its application in relieving stress, fatigue, invigoration and vitality and its anti-aging properties and its application for relaxation therapy. Yoga has become more popular than ever, with celebrities, politicians, business people, and almost every walk of life currently practicing. The word yoga is Sanskrit for Yoke, or union. In the practice of yoga we seek to create union between the mind and body. Yoga is dynamite to make you feel younger and healthy with heightened mental prowness. Longer life often results from following yogic ways of health maintenance. When both external dangers and internal diseases and habits leading to degeneration have been removed, one naturally lives healthy and longer.

Keywords: Yoga, Health, Diseases

The aim of this paper is to explore how yoga is beneficial for health to see the goodness of yoga for improving health and decrease the chances of diseases. The term Yoga comes from the root yuj, "to yoke or join."Here it is used to mean the Union of the individual spirit with the Universal Spirit. The art of Yoga is defined as a system of Culture for perfecting human efficiency. It claims to destroy the defects and diseases of the body and mind, to establish health and bestow happiness, to develop intelligence, and reveal true knowledge of self, and to extract the nectar of all things. The term yoga as this word is part of an entire system that is quite complex. The word yoga as interpreted by many, means "union” and can be broken down further into five specific elements all contributing to the union of mind, body and soul. Jnana, Bhakti, Karma, Raja and Hatha yoga are the different elements of yoga. Karma yoga is the yoga of action, Bhakti yoga is the yoga of devotion, Jnana is the yoga of knowledge, Raja is the yoga of the mind and Hatha is

\footnotetext{
${ }^{1}$ Research scholar, Department of psychology, AMU, Aligarh

*Responding Author

(C) 2016 I R Saleem; licensee IJIP. This is an Open Access Research distributed under the terms of the Creative Commons Attribution License (http://creativecommons.org/licenses/by/2.0), which permits unrestricted use, distribution, and reproduction in any Medium, provided the original work is properly cited.
} 


\section{Yoga Benefits for Health}

the yoga of the body. All elements of yoga are equally important when creating a necessary balance for those individuals who practice it. Yoga is considered by society as part of a wellness practice for adults and is widely accepted in many workplaces as having clear benefits to employee work production and personal well-being as seen by the recent increase in wellness programs being implemented in major corporations. For example, Microsoft implemented a Weight Management program in 2005 to increase the physical fitness of employees and therefore reduce employee absenteeism (McPherson, 2005). Yoga helps us to take away the stress and frustration improve physical and mental health to increase personal satisfaction and well-being Yoga is specifically mentioned as an example of a fitness activity in the new curriculum under the larger category of Movement Competence (Health and Physical Education, 2010, pg.140). A study published in the Journal of Asthma looked at six young asthmatics with a history of childhood asthma that went through yoga training for two years. The study concluded that practicing yoga is beneficial for asthmatics because it "increased pulmonary function and exercise capacity” (Jain, 1991, pg.440).

Researchers have discovered that the regular practice of yoga may produce many health benefits, including increased fitness and normalization of blood pressure. Yoga is a renowned antidote to stress. Over time, yoga practitioners report lower levels of stress and increased feelings of happiness and wellbeing. This is because concentrating on the postures and the breath acts as a powerful form of meditation. Yoga is non-competitive and suitable for anyone, regardless of their age or fitness level. Your yoga teacher should carefully guide and observe you, and modify postures when necessary. An asana should never cause pain. If it hurts, ease back on the stretch or don’t do it at all. It is important to keep within your physical limits. If you are over 40, haven’t exercised for a long time or have a pre -existing medical condition, you should check with your doctor before starting any regular exercise routine.

\section{Yoga Benefits for health}

The physical building blocks of yoga are the posture (asana) and the breath. A series of poses held in time with breathing, exercises every part of the body. Benefits include:

Yoga is increased strength, endurance, flexibility, and balance, which also translates into an increased ability to perform activities, have more energy, and get a more restful sleep. Most of the diseases take their origin in over-eating, sexual excess and outbursts of anger and hatred. If the mind is kept cool and calm at all times, you will have wonderful health, strength and vitality. Energy is depleted by fits of anger. The cells and tissues are filled with morbid, poisonous materials, when one loses his temper and entertains deep hatred. Various sorts of physical ailments crop up. The blood becomes hot and thin and consequently night pollution results. Various kinds of nervous diseases are attributable to excessive loss of the seminal energy and frequent fits of explosive anger or wrath. 


\section{SOME IMPORTANT BENEFITS OF YOGA FOR HEALTH ARE AS FOLLOWS}

Yoga Builds muscles strength: Strong muscles do more than look good. They also protect us from conditions like arthritis and back pain, and help prevent falls in elderly people. And when you build strength through yoga, you balance it with flexibility. If you just went to the gym and lifted weights, you might build strength at the expense of flexibility.

Yoga improves posture: Increased flexibility and strength helps you improve your posture. With better core strength and the body awareness you create by practicing yoga, you are more likely to recognize when you are slouching or have bad posture and correct it. Poor posture can cause back, neck, and other muscle and joint problems.

Yoga Prevents cartilage and joint breakdown: Each time you practice yoga, you take your joints through their full range of motion. This can help prevent degenerative arthritis or mitigate disability by “squeezing and soaking” areas of cartilage that normally aren’t used. Joint cartilage is like a sponge; it receives fresh nutrients only when its fluid is squeezed out and a new supply can be soaked up. Without proper sustenance, neglected areas of cartilage can eventually wear out, exposing the underlying bone like worn-out brake pads.

Yoga Increases blood flow: Yoga increases blood flowing. The relaxation exercises can help your circulation, especially in your hands and feet. Yoga also gets more oxygen to your cells, which function better as a result. Twisting poses are thought to wring out venous blood from internal organs and allow oxygenated blood to flow in once the twist is released.

Yoga Drains lymphs and boosts immunity: When you contract and stretch muscles, move organs around, and come in and out of yoga postures, you increase the drainage of lymph (a viscous fluid rich in immune cells). This helps the lymphatic system fight infection, destroy cancerous cells, and dispose of the toxic waste products of cellular functioning.

Lowers blood sugar: Yoga lowers blood sugar and LDL ("bad”) cholesterol and boosts HDL ("good”) cholesterol. In people with diabetes, yoga has been found to lower blood sugar in several ways: by lowering cortisol and adrenaline levels, encouraging weight loss, and improving sensitivity to the effects of insulin. Get your blood sugar levels down, and you decrease your risk of diabetic complications such as heart attack, kidney failure, and blindness.

Maintains nervous system: Some advanced yogis can control their bodies in extraordinary ways, many of which are mediated by the nervous system. Scientists have monitored yogis who could induce unusual heart rhythms, generate specific brain-wave patterns, and, using a meditation technique, raise the temperature of their hands by 15 degrees Fahrenheit. If they can use yoga to do that, perhaps you could learn to improve blood flow to your pelvis if you're trying to get pregnant or induce relaxation when you're having trouble falling asleep. 


\section{Yoga Benefits for Health}

Yoga gives a peace of mind: Yoga quells the fluctuations of the mind, according to Patanjali's Yoga Sutra. In other words, it slows down the mental loops of frustration, regret, anger, fear, and desire that can cause stress. And since stress is implicated in so many health problems from migraines and insomnia to lupus, MS, eczema, high blood pressure, and heart attacks if you learn to quiet your mind, you'll be likely to live longer and healthier.

Eases your pain: Yoga can ease your pain. According to several studies, asana, meditation, or a combination of the two, reduced pain in people with arthritis, back pain, fibromyalgia, carpal tunnel syndrome, and other chronic conditions. When you relieve your pain, your mood improves, you're more inclined to be active, and you don't need as much medication.

Yoga is the perfect example of holistic health because of this combination of mind and body. After all the body cannot exist without the mind and vice versa. Yoga has become more popular than ever, with celebrities, politicians, business people, and almost every walk of life currently practice. Yoga is a multidisciplinary tool extremely useful to purify the mind and body and gain control over our minds and emotions. Yoga is also the most popular means for selftransformation and physical wellbeing. It is useful for both the wordily people seeking mental peace and ascetics seeking liberation. Yoga helps you to become a better person, a better human being and a better devotee.

\section{PURPOSE OF YOGA FOR HEALTH}

The original context of yoga was spiritual development practices to train the body and mind to self observe and become aware of their own nature. The purposes of yoga were to cultivate discernment, awareness, self-regulation and higher consciousness in the individual. As the split occurring between those seeking physical developments versus those seeking spiritual development has widened, the lack of awareness and attention to inner experience has disconnected the practitioner from his body. In the modern world we have become quite successful in our external achievements--we have created powerful technologies and a variety of products, we are obsessed with accumulating power, wealth, property and objects--and yet we have not been able to create either individual or social peace, wisdom, or happiness. We have only to look around and see the destructiveness of our weapons, the emptiness of our pleasures and entertainments, the misuse of our material and personal resources, the disparities between rich and poor, and above all, the loneliness and violence of our modern world. We see that amid all our success in the external world, we have accomplished little of lasting value. These problems will not be solved through new technological developments. Instead, the resolution to these human problems will come only when we discover within ourselves that for which all of mankind is searching--inner peace, tranquility, and wisdom. This attainment is the goal of yoga, for yoga is the practical science intended to help human beings become aware of their ultimate nature. For those who want to follow the path of yoga towards peace and evolution, there are a few prerequisites. We need good health, a calm mind, sincerity, and a burning desire to rise above our human imperfections. Our health is maintained by a simple and well- regulated diet, 


\section{Yoga Benefits for Health}

adequate sleep, some physical exercise, and relaxation. Imbalance or excesses in food, exercise, sleep, or our personal relationships produce physical and emotional disruptions that disturb the practice of yoga and meditation. If the aspects of our daily lives are well balanced, then certainly we can make progress in yoga in the modern world. Regardless of where we live or what we do, we can create a life conducive to yoga.

\section{SCOPE OF YOGA}

Yoga is certainly more than mastering its postures and asanas and increasing the strength and flexibility of body. It indicates towards healing of mind and body and attaining the state of self enlightenment. It is said that in early periods when Yoga was just introduced, the main purpose was to heal community members and the practitioners act as religious mediators. The exact origin of Yoga is uncertain but collecting the small pieces together takes us to a valid conclusion. It is said that Yoga originated into the west and the first sign appeared in ancient Shamanism that date back to some 3000 B.C. Evidence of Yoga can also be found in Rig Veda. The word Yoga provides a sense of peace which certainly derived from the etymology of the word. The word has been taken from the Sanskrit word 'Yuj' which means unite or join. This word unite has been taken in the sense of uniting the individual with cosmic consciousness. Needless to say, practicing of Yoga includes the traditional aspects too such as practicing different poses, chanting of mantra, observing breathing habit and controlling thoughts coming to mind with the help of meditation. Today, it has been practiced for fitness, healthy body and mind, strength, flexibility, emotional well-being and much more. The main purpose of practicing Yoga is to taking control over the body, mind and emotional aspects. The cessation of bad thoughts creates a positive vibe around the person and makes him healthy overall.

The researchers found that prisoners after a ten-week yoga course reported improved mood, reduced stress and were better at a task related to behaviour control than those who continued in their normal prison routine.

\section{CONCLUSION}

Yoga practice is safe and can bring many health benefits to practitioners, whether they are young, old, healthy, recovering from illness or looking for a therapeutic option to help them to manage a chronic condition. . The beauty of Yoga is that it can be practiced by anyone. It doesn't matter how old you are or what shape you are in. If you desire a more limber body, Yoga is one of the quickest ways to attain it. Yoga also increases an individual's physical coordination and promotes better posture. And it does all this without potentially hazard negative effects that are often incurred in high-impact forms of exercise. When performed properly, in conjunction with proper related breathing techniques, Yoga helps stimulate the circulatory system, the digestive process as well as the nervous and endocrine system. Yoga is dynamite to make you feel younger with heightened mental prowness. Longer life often results from following yogic ways of health maintenance. When both external dangers and internal diseases and habits leading to degeneration have been removed, one naturally lives longer. 


\section{REFERENCES}

Jain, S. (1991). Effects of Yoga Training on Exercise Tolerance in Adolescents with Asthma. The Journal of Asthma, 28, 437-442.

McPherson, T. (2005). Microsoft Weight Management Program. Power Point Presentation by Senior Benefits Manager. December 14, 2005.

Spiritual Essays (http://www.hinduwebsite.com/divinelife/essayindex.asp)

\section{Websites}

www.betterhealth.vic.gov.au(“Health and Yoga.Com,” n.d.).

http://www.healthandyoga.com/html/yoga/Benefits.aspx

http://holisticonline.com/yoga/hol_yoga_benefits.htm

http://www.hinduwebsite.com/links.asp

http://www.swamij.com/yoga-meaning.htm

http://www.nytimes.com/roomfordebate/2012/01/12/is-yoga-for-narcissists/the-purpose-of-yoga http://www.cyberastro.com/health/yoga_about.asp

http://www.medindia.net/news/yoga-improves-mental-health-among-prisoners-121822-1.htm 